\title{
EURO FOOD CHEM VI
}

The Sixth European Conference on Food Chemistry on the subject "Strategies for Food Quality Control and Analytical Methods in Europe" (FECS event no. 168) was held on September 22-26, 1991, at Hamburg, Chemical Institutes of the University. It was organized by the Working Party on Food Chemistry (WPFC) of the Federation of European Chemical Societies (FECS) and the Lebensmittelchemische Gesellschaft, a division of the Gesellschaft Deutscher Chemiker (GDCh), as a joint congress with the Deutscher Lebensmittelchemikertag 1991. This resulted in a very successful meeting.

Since the completion of the EC market in 1993 will have major consequences across Europe as a whole, the predominant aim of Euro Food Chem VI was to address problems and requirements for European food control and consumer protection and to identify opportunities for cooperation and interaction. For this reason, 9 invited plenary lectures were given, dealing with the quality of food and with efficient food control by manufacturers and official authorities as well as with the qualification of experts and the competence of laboratories, both required as a basis for the mutual recognition of results. Moreover, 25 short communications and 145 poster presentations addressed the following areas:

- General aspects of food quality and food control

- Raw materials, food processing, use of additives etc.

- Basic research on components of raw and processed food

- Analytical methods for food research and food control
- Food contamination: analytical methods and results - Nutrition

As a prelude to the conference, the Chairman of the FECS Council, Dr. W. Fritsche, awarded the FECS Honorary Medal for Merit to Prof. Dr. P. CzedikEysenberg, Vienna, who has chaired the WPFC with particular effort and success since it was established 15 years ago.

Euro Food Chem VI was attended by 827 food chemists and other food scientists representing industry, universities and research institutions, official control authorities and public analysts from 21 European countries. For the convenience of the participants, a simultaneous translation between English and German was provided during lectures and discussions. Furthermore, the international dialogue was stimulated by an exhibition of books, chemicals and laboratory equipment and by the social programme including boat cruises on the Alster lake and the river Elbe. The Conference Proceedings (in English, 2 volumes, XXXIV + 945 pages) were prepared in time for distribution in Hamburg; additional copies are still available from Behr's Verlag, Averhoffstrasse 10, W-2000 Hamburg 76, Federal Republic of Germany, for DM 150.- incl. VAT. The closing ceremony invited all European food scientists to attend Euro Food Chem VII which is scheduled to take place on September 22-24, 1993, in Valencia, Spain, and will focus on fermented foods. 